*Proceedings*

\title{
Investigation of Surface Alteration of Microplastics by Using UV Irradiation ${ }^{\dagger}$
}

\author{
Nina Maria Ainali ${ }^{1,2 *}$, Dimitra Lambropoulou ${ }^{1}$ and Dimitrios N. Bikiaris ${ }^{2 *}$ \\ 1 Laboratory of Environmental Pollution Control, Department of Chemistry, Aristotle University of \\ Thessaloniki, GR-541 24 Thessaloniki, Greece \\ 2 Laboratory of Polymer Chemistry and Technology, Department of Chemistry, Aristotle University of \\ Thessaloniki, GR-541 24 Thessaloniki, Greece \\ * Correspondence: nsainali@chem.auth.gr; dbic@chem.auth.gr; Tel.: +2310-997-812 \\ + Presented at the First International Conference on "Green" Polymer Materials 2020, 5-25 November 2020; \\ Available online: https://cgpm2020.sciforum.net/.
}

Published: 4 November 2020

\begin{abstract}
Microplastics are formed by the degradation of plastic wastes under the action of physicochemical mechanisms in environment, existing as contaminants of emerging concern in recent years due to their adverse impact on living organisms and the environment. When common polymers are exposed to the environment are adversely affected by solar radiation (primarily ultraviolet (UV) UV-B), which initiates photooxidative degradation leading to polymer chain breakdown, causing though the deterioration of their mechanical properties after an unpredictable time. In the present study, to improve understanding of characteristics and mechanism of microplastics, four of the most widely used polymers covering a wide spectrum of applications, due to their excellent chemical inertness and high processability such as low-density polyethylene (LDPE), high-density polyethylene (HDPE), polypropylene (PP) and polystyrene (PS) in the form of thin films were exposed to UV radiation at $254 \mathrm{~nm}$ with constant temperature for several times. After exposure (5, 10, 20, 30, 45 and 60 days), the films were removed from the chamber and UV irradiation influence was evaluated by using FTIR (Fourier-Transform Infrared) Spectroscopy, DSC (Differential Scanning Calorimetry), XRD (X-Ray Diffraction), Py-GC/MS (Pyrolysis-Gas Chromatography/Mass Spectroscopy), SEM (Scanning Electron Microscopy), while their mechanical properties were also evaluated.
\end{abstract}

Keywords: microplastics; degradation; aging; photooxidation; UV exposure

\section{Introduction}

In the modern world, plastic field is staying ubiquitous to everyday lives since it remains lightweight, long-lasting, and low-cost. Hence, especially during the second part of the 20 $0^{\text {th }}$ century, production of plastics, destined for packaging, building or medical applications, has considerably expanded. To understand the develop of this statement, useful is the estimation that by 2050, only plastic waste will reach approximately $12,000 \mathrm{Mt}$, according to the current plastics' production and garbage handling [1]. In fact, commercial plastic waste further degrade into microplastics (MPs) under the action of many physicochemical mechanisms (ultra-violet and solar radiation, temperature and thermal cycling, humidity, environmental pollutants, abrasion, rain, etc) in environment, making them as evolving contaminants nowadays due to their adverse impact on living organisms and the environment [2-6]. Exposure to UV-B radiation is one of the most significant mechanism in bringing about rapid photodegradation in synthetic polymers, since it initiates both cross-linking of the polymer matrix and chain scission reactions, resulting in reorientation of the macromolecular chains and finally polymer chain collapse. The latest breakdown is responsible for the deterioration of 
polymers' mechanical behavior after an unpredictable time, creating though useless and contaminating materials [7-9].

The present study was carried out to boost the understanding of characteristics and mechanism of MPs; four of the most extensively used polymers covering a wide spectrum of applications were examined. Low-density polyethylene (LDPE), high-density polyethylene (HDPE), polypropylene (PP) and polystyrene (PS) in the form of thin films were exposed to UV-B radiation at $254 \mathrm{~nm}$ with constant temperature and humidity for several times. After selected time intervals $(5,10,20,30,45$ and 60 days of UV exposure), the films were removed from the chamber and UV irradiation impact was evaluated. FTIR spectroscopy revealed the formation of new groups during UV exposure, while XRD, DSC and mechanical measurements boosted the noticeable impact of UV irradiation on their crystalline, thermal and mechanical properties. SEM micrographs revealed the significant morphological alterations, revealing extended decomposition after just 30 days of exposure. Finally, the mechanism of thermal degradation of the four polymers before and after UV exposure was studied by Py-GC/MS.

\section{Experiments}

\subsection{Materials}

Low density polyethylene (LDPE) suitable for general packaging and shrink film was supplied by Repsol Química (Madrid, Spain) possessing the trade name ALCUDIA ${ }^{\circledR}$ PE033 with melt flow 0.3 $\mathrm{g} / 10 \mathrm{~min}$ (ISO 1133). High density polyethylene (HDPE) appropriate for packaging and agricultural uses was supplied by Total Petrochemicals (Brussels, Belgium) under the trade name M5510EP ${ }^{\circledR}$ with specific gravity $0.955 \mathrm{~g} / \mathrm{cc}$ (ISO 1183) and melt flow $12 \mathrm{~g} / 10 \mathrm{~min}$ (ISO1133). Polypropylene (PP) was kindly supplied from Hellenic Petroleum (Marousi, Greece) under the trade name ECOLEN ${ }^{\circledR}$ HZ40P appropriate for continuous filaments and staple fibers, with a melt flow rate of $12 \mathrm{~g} / 10 \mathrm{~min}$ (ASTM D 1238). Polystyrene (PS) appropriate for packaging containers was finally supplied by Sigma Aldrich (Steinheim, Germany) with melt index $4.00 \mathrm{~g} / 10 \mathrm{~min}$ (ASTM D 1238).

\subsection{Preparation of films and UV irradiation process}

Relative thin sheets of about $450 \pm 50 \mu \mathrm{m}$ (7 films for each polymer type) were prepared using an Otto Weber, Type PW 30 hydraulic press connected with an Omron E5AX Temperature Controller, set at a temperature of $200 \pm 5^{\circ} \mathrm{C}$. The moulds (with dimensions of $9.2 \times 5.3 \mathrm{~cm}$ ) were slowly cooled and pressed as to avoid the formation of a rough surface. In order to measure the mechanical properties from these sheets dumb-bell-shaped tensile test specimens (central portions $5 \times 0.5 \mathrm{~mm}$ thickness, $22 \mathrm{~mm}$ gauge length) were engraved in a Wallace cutting press.

Polymers in the form of thin films were exposed to UV irradiation (chamber BS-09) at $254 \mathrm{~nm}$ at constant temperature $\left(25^{\circ} \mathrm{C}\right)$ and relative humidity $(50 \%)$ for several days. The irradiation intensity films were exposed at a distance of $20 \mathrm{~cm}$ from the lamp. The films were about $500 \mathrm{~W} / \mathrm{m}^{2}$ at an irradiated area of $35 \times 45 \mathrm{~cm}^{2}$, and the films were irradiated continuously for $7 \mathrm{~h}$, remaining at room temperature for $7 \mathrm{~h}$, and irradiated again. In order to irradiate both surfaces, the films were flipped once every day. After exposure the films were removed from the chamber (after 5, 10, 20, 30, 45 and 60 days of UV exposure) and the effect of UV exposure was evaluated by using FTIR spectroscopy, measurements of mechanical properties, DSC, WAXD and SEM microscopy. Furthermore, the mechanism of thermal degradation of the four polymers before and after UV exposure was studied by Py-GC/MS.

\subsection{Characterization of the studied polymers}

FTIR spectra before and after UV irradiation were obtained using a Perkin-Elmer FTIR spectrometer, model Spectrum One (Dresden, Germany). The four utilized polymers were in the form of thin films with thickness of approximately $20 \mathrm{~mm}$ (one film for each material) and placed in aluminum holders with the appropriate dimensions of spectrometer's accessory. The IR spectra of 
these films were obtained in absorbance mode and in the spectral region of $450-4000 \mathrm{~cm}^{-1}$ using a resolution of $4 \mathrm{~cm}^{-1}$ and 32 co-added scans.

UV irradiated and engraved films were studied for their tensile mechanical properties utilizing an Instron 3344 Dynamometer (Norwood, MA, US) in accordance with ASTM D638, using a crosshead speed of $50 \mathrm{~mm} / \mathrm{min}$ for LDPE and HDPE, and a analogous rate of $5 \mathrm{~mm} / \mathrm{min}$ for PP and PS polymers. The values of Young's modulus, yield stress, elongation at break and tensile strength at the break point were determined. At least five specimens were tested for each sample and the average values are reported.

Thermal analysis of the composites before and after exposure to UV radiation was performed using a Differential Scanning Calorimeter (Perkin Elmer, Pyris Diamond, Waltham, MA, US), calibrated with Indium and Zinc standards. For each measurement a sample of $6.0 \pm 0.2 \mathrm{mg}$ was used, placed in a sealed aluminum pan, and heated to $130{ }^{\circ} \mathrm{C}$ for LDPE, $150{ }^{\circ} \mathrm{C}$ for HDPE, $170{ }^{\circ} \mathrm{C}$ for PP, $300{ }^{\circ} \mathrm{C}$ for PS at a scanning rate of $20^{\circ} \mathrm{C} / \mathrm{min}$ in an inert atmosphere $\left(\mathrm{N}_{2} 50 \mathrm{~mL} / \mathrm{min}\right)$ and held at this temperature for $2 \mathrm{~min}$ in order to erase any thermal history. Afterwards, the sample was cooled down to $30{ }^{\circ} \mathrm{C}$ at a cooling rate of $20{ }^{\circ} \mathrm{C} / \mathrm{min}$, held at $30{ }^{\circ} \mathrm{C}$ and heated again to the abovementioned temperatures with a heating rate of $10^{\circ} \mathrm{C} / \mathrm{min}$.

SEM studies of films' surface before and after exposure to UV radiation were carried out using a JEOL JMS-840A (Freising, Germany) scanning microscope equipped with an energy dispersive Xray (EDX) Oxford ISIS 300 micro-analytical system.

X-ray diffraction patterns of the polymer samples were completed using a MiniFlex II XRD system from Rigaku Co (Tokyo, Japan), with CuKa radiation $(\lambda=0.154 \mathrm{~nm})$ in the angle $2 \theta$ range from 5 to $60^{\circ}$.

For Py-GC/MS analysis, a very small amount $(5 \mathrm{mg})$ of each sample is "dropped" initially into the "Double-Shot" EGA/PY-3030D Pyrolyzer (Frontier Laboratories Ltd., Fukushima Japan). The preselected pyrolysis temperature was $550{ }^{\circ} \mathrm{C}$ and the GC oven temperature was heated from 50 to 300 ${ }^{\circ} \mathrm{C}$ at $10{ }^{\circ} \mathrm{C} / \mathrm{min}$. Sample vapors generated in the furnace were split (at a ratio of $1 / 50$ ), a portion moved to the column at a flow rate of $1 \mathrm{~mL} / \mathrm{min}$, pressure $53.6 \mathrm{kPa}$ and the remaining portion exited the system via the vent. The pyrolyzates were separated using temperature programmed capillary column of a Shimadzu QP-2010 Ultra Plus (Japan) gas chromatogram and analyzed by the mass spectrometer MS-QP2010SE of Shimadzu (Japan). Ultra-ALLOY ${ }^{\circledR}$ metal capillary column from Frontier Laboratories LTD (Fukushima Japan) was utilized (containing 5\% diphenyl and 95\% dimethylpolysiloxane stationary phase, column length $30 \mathrm{~m}$ and column ID $0.25 \mathrm{~mm}$ ). For the mass spectrometer the succeeding conditions were preferred: Ion source heater $200{ }^{\circ} \mathrm{C}$, interface temperature $300{ }^{\circ} \mathrm{C}$, vacuum $10^{-4}-10^{\circ} \mathrm{Pa}, \mathrm{m} / \mathrm{z}$ range $45-500 \mathrm{amu}$ and scan speed 10,000 . The chromatogram and spectra retrieved by each experiment were subject to further interpretation through Shimadzu and Frontier post-run software.

\section{Results and discussion}

\subsection{Mechanical properties}

As easily observable from the data (Figure 1), the strain at the breaking point $(\varepsilon b)$, correlated to the time of UV exposure, depicted a similar profile in the case of LDPE, HDPE and PP; a strong and rapid decrease for short exposure times (first 5, 10 and 30 days for PP, HDPE and LDPE, respectively), followed by almost constant values up to the 60 days of UV irradiation. In the case of PP, the mechanical measurements were impossible after the 20 days of UV exposure, since the polymer specimens collapsed. A rather differianted pattern was observed for PS, since an increasing tendency of elongation at break till the first 10 days of irradiation was observed, proceeded from a fast drop in this trend, maybe due to the cross-linking reactions took place beyond chain scission during the UV exposure. In fact, the amount of gel rises during irradiation existing predominantly in the amorphous region [10]. 

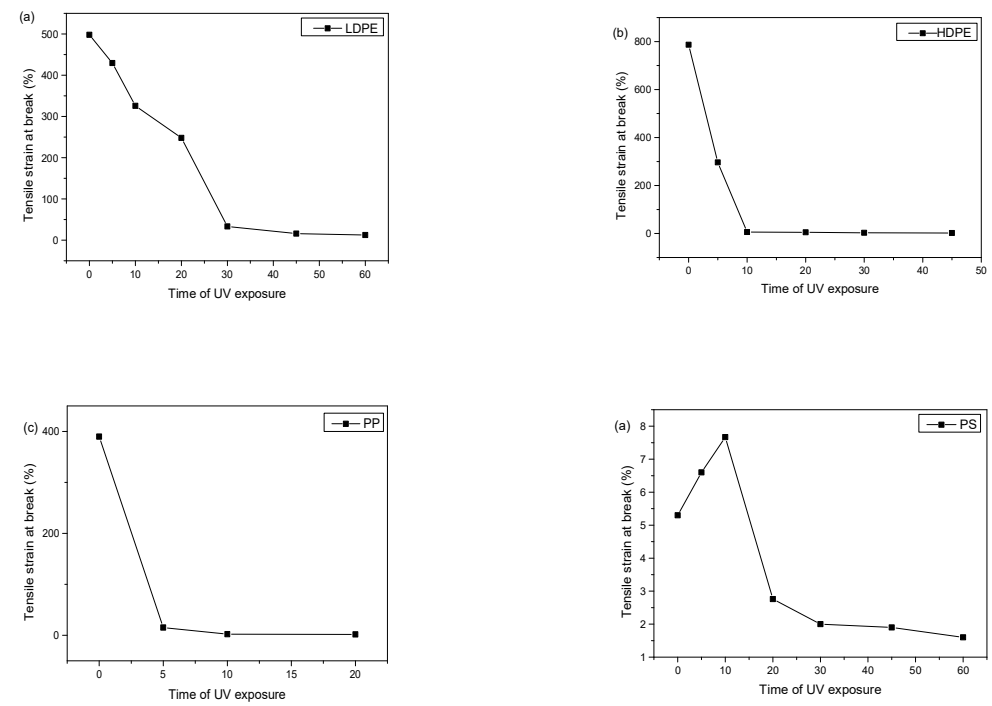

Figure 1. Variation of tensile strength at break point for a) LDPE, b) HDPE, c) PP and d) PS during several days of UV exposure.

\subsection{Chemical structure changes}

To further support the results of mechanical properties' characterization, FTIR spectroscopy was utilized to evaluate the chemical changes that occurred during the UV-irradiation period. In general, polyolefines photo-degrade though two separate pathways. Firstly, Norrish type I mechanism is related with the formation of carbonyl groups, while Norrish type II leads to the creation of vinyland hydroxyl/hydroxyperoxide species [8]. Norrish type II mechanism is responsible for the deterioration in polymers' mechanical properties due to the oxygen uptake. Furthermore, unsaturation plays also a major role at chain scission forced by weaker C-C bonds, while crosslinking processes also occur [11,12]. As a matter of the fact, on LDPE, HDPE and PP's FTIR spectra alterations appeared during UV irradiation in the regions of $3300-3500 \mathrm{~cm}^{-1}(-\mathrm{OH})$ and $1610-1800 \mathrm{~cm}-1(-\mathrm{C}=\mathrm{C}-)$ should be further appreciated [13]. Indeed, neat LDPE, HDPE and PP revealed expanded peaks in these regions, indicating the oxidation of the polymeric structures. Moreover, the band at 1700-1800 $\mathrm{cm}^{-1}$ broadened as UV exposure time increased, since $\gamma$-lactones, esters, carboxylic acids and conjugated ketones were formed. However, in the cases of HDPE and PP, the peak's increase in 1650$1860 \mathrm{~cm}^{-1}$ region, outlining the presence of carbonyl species, was more abrupt after 45 days of UV exposure. Notable is the case of PP, where the aforementioned peak increase was observed after only the first 5 days of radiation; fact reinforced also by the mechanical properties' measurements. In addition, a slight narrow peak appeared at the area of $1625-1660 \mathrm{~cm}^{-1}$ revealed the development of unsaturation in the irradiated polymers. In PS case, the only noteworthy alteration observed FTIR spectra, was the one occurred at $\mathrm{C}=\mathrm{O}$ and $\mathrm{C}-\mathrm{O}$ stretching bands indicating oxidation processes. Interesting is the absence of any sign of hydroxylation; a broad absorption band which would appear in the $3600-3200 \mathrm{~cm}^{-1}$ region. Due to the overlapping peaks, the degree of chain scission and crosslinking reactions could not be estimated for PS through FTIR measurements.

A quantification of the obtained results was considered essential to outline the photo-oxidation process and though, the areas of the created bands in the spectra were calculated and expressed as carbonyl, hydroxyl and vinyl indexes. Carbonyl (equation (1)), vinyl and hydroxyl/hydroxyperoxide indexes were calculated using the areas of the created bands in the spectra (1720, 1640 and 3150-3650 $\mathrm{cm}^{-1}$ respectively) and a stable peak as a reference accordingly. In the presented study, the band at $2018 \mathrm{~cm}^{-1}$ was used as a reference peak, while all the measurements were adjusted to the initial concentration that might have occurred at the unirradiated samples [14]. 


$$
\text { C.I. }(\%)=\frac{A_{1720}-A_{1720}^{0}}{A_{2018}} \times 100
$$

where:

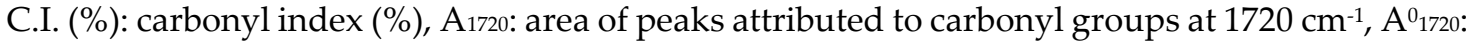
area of peak attributed to carbonyl groups at $1720 \mathrm{~cm}^{-1}$ of unirradiated samples, A2018: area of reference peak at $2018 \mathrm{~cm}^{-1}$. For vinyl index (V.I.), as well as for hydroxyl/hydroxyperoxide index (H.H.I.), the same equation was utilized, after altering $A_{1720}$ to $A_{1640}$ and $A_{3150-3650,}$ respectively. The acquired indices are demonstrated in comparative graphs (Figure 2) for LDPE, HDPE and PP.
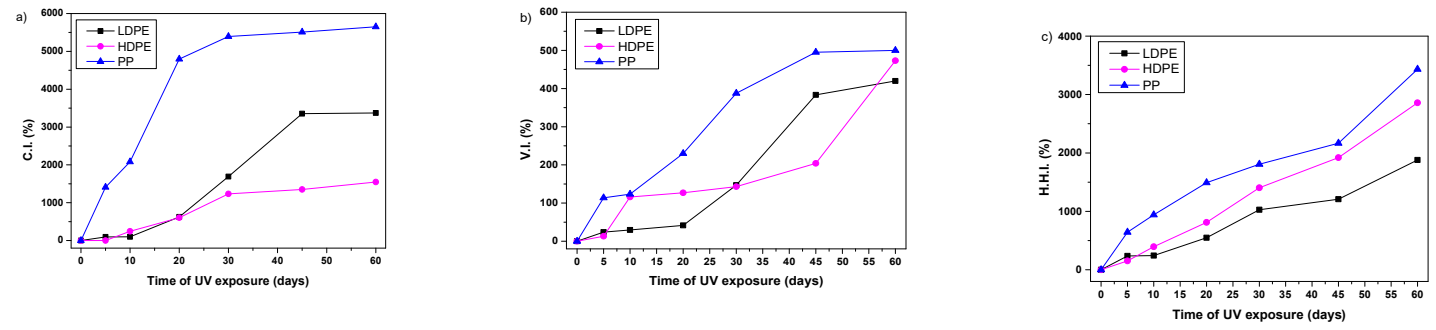

Figure 2. a) Carbonyl index, b) vinyl index and c) hydroxyl/hydroxyperoxide index of LDPE, HDPE and PP during UV exposure for different days.

In all cases, the obtained graphs presented an increasing tendency in C.I., V.I. and H.H.I. indices. However, UV degraded samples are much poorer in vinyl groups leading to the statement that the dominating mechanism is the chain scission and the formation of both carbonyl and hydroxyl/ hydroxyperoxide species.

\subsection{Differential Scanning Calorimetry (DSC)}

Significant role to the alterations of the mechanical properties of the materials holds their degree of crystallinity and though a study of thermal properties was performed as well. According to the recorded thermographs (Figure 3), exposure to UV irradiation had an effect on the melting temperatures of LDPE, HDPE and PP, while the glass transition temperature of PS was also affected. For the first three studied polymers (Figure 3a), the same pattern is followed; a progressing shift of their melting point to lower temperatures as irradiation time increases, exists. Although, till the first 20 days of irradiation a small increase in crystallinity is observed; an outcome of chain scission occurring in amorphous regions, leaving the unchained segments to crystallize inside the polymer matrix. Besides, the rise in crystallinity with simultaneous chain decomposition, also, conduces to the embrittlement of the samples and therefore to the decline of elongation at break during UV exposure. In PS case (Figure $3 b$ ), an increase in glass transition temperature $\left(T_{g}\right)$ is depicted until the $30^{\text {rd }}$ day of UV exposure, while afterwards a decline is noticed. Between 30 and 60 days of UV irradiation, the $\mathrm{Tg}$ declines by $1.64^{\circ} \mathrm{C}$, owing to either chain scission reactions which deteriorate the average molecular mass, or to photo-chain oxidation mechanisms decreasing the molecular mass of PS and removing steric hindrances from the polymer chains.
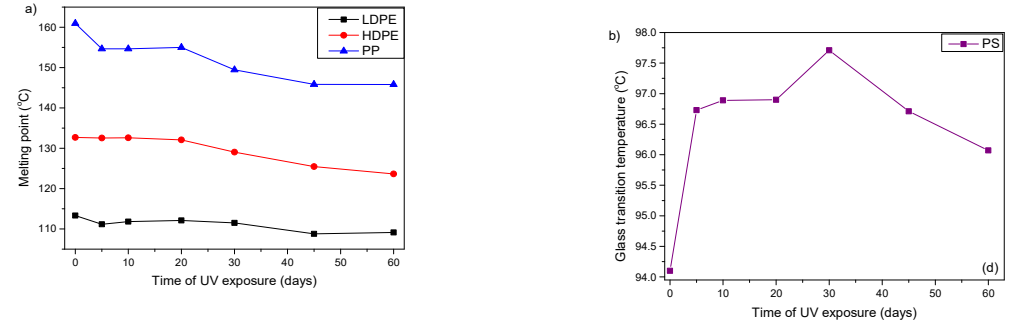

Figure 3. Variation of a) melting point in LDPE, HDPE, PP and $\mathbf{b}$ ) glass transition temperature on PS films after UV exposure. 


\subsection{Morphological examination of UV irradiated samples}

SEM analysis on the surface of LDPE, HDPE, PP and PS films was carried out to detect any changes provoked by photo-oxidation to the different samples. Several micrographs were recorded for unirradiated and irradiated films after 30 and 60 days of UV exposure, and the changes observed are depicted in Table 1 . In all cases, the films' surface was initially fairly smooth and unwrinkled, while after irradiation, noteworthy morphological alterations appeared, since the surface of films become rougher. Additionally, holes and defects were designed in the studied surfaces, indicating decomposition of polymer matrixes; an outcome in compliance with mechanical properties measurements and Py-GC/MS analysis. Generally, the tested specimens became brittle after the 30 days of irradiation, while in the case of PP this behavior initiated earlier. Instead, in PEs occasion the observed alterations were mild for the first 30 days, becoming more intense gradually. As for PS, a rather different structure of surficial cracks after 30 days of irradiation appeared, since the latest appeared as parallel lines, enriched with clear holes after the 60 days of UV exposure. All these remarks are in well agreement with the results of both the mechanical properties measurements and FTIR spectra.

Table 1. SEM micrographs of LDPE, HDPE, PP and PS after 0, 30 and 60 days of UV exposure.

\begin{tabular}{|c|c|c|c|c|}
\hline Days of UV exposure & LDPE & HDPE & PP & PS \\
\hline 0 & & & & \\
\hline 30 & & & & \\
\hline 60 & & & & \\
\hline
\end{tabular}

\subsection{Pyrolysis-gas chromatography/mass spectroscopy study}

In order to further explore the effect of UV irradiation for the four studied polymers, Py-GC/MS was utilized to demonstrate in which extend was the degradation path affected. According to literature, polyolefines degrade initially through random chain-scission reactions, followed by $\beta$ scission propagation, radical reactions and finally termination, resulting in the fragmentation of the primary polymer chain into smaller straight chain fragments of diverse length [8][15]. PE and PP chromatographs consisted of the characteristic triplet peaks, with no special differences detected between the samples concerning the retention time, while all pyrolyaed components were identified as a series of hydrocarbons with an increasing number of carbon atoms. The first peak of each triplet set corresponds to $\alpha, \omega$-diene, the second to $\alpha$-alkene and the final to $n$-alkane [16]. Nevertheless, the ratio of the respective amounts of the initial peaks ( $\mathrm{Rt}=0-6 \mathrm{~min}$ ) attributed to low molecular weight compounds, to the relative of higher molecular weight hydrocarbons (Rt $>6 \mathrm{~min}$ ), differentiates as UV exposure proceeds. As illustrated in Table 2, UV exposure provokes the initial cracking of the large hydrocarbon molecules into smaller olefins, provoking though the aforementioned increasing tendency. During PS decomposition, styrene (m/z 104), its dimer (m/z 208) and trimer (m/z 312) are the most plentiful byproducts, formed via continuous $\beta$-scission of macromolecular ends. In the recorded chromatographs (not showed for briefness reasons), the ratio of trimer peak areas to dimer and styrene, is progressively decreasing. The abovementioned statements force the result that throughtout the irradiation time, an increase in the rate of degradation due to the progressing chain scission reactions is detected. 
Table 2. Ratios of PE's peak areas of the hydrocarbons with more than 10 carbon atoms to hydrocarbons up to 9 carbon atoms.

\begin{tabular}{cccc}
\hline Sample name & Ratio & Sample Name & Ratio \\
\hline LDPE 0 days & 6.98 & HDPE 0 days & 7.54 \\
\hline LDPE 30 days & 4.83 & HDPE 30 days & 6.13 \\
\hline LDPE 60 days & 1.22 & HDPE 60 days & 5.42 \\
\hline
\end{tabular}

\section{Conclusions}

This study provides an insight into the effects of UV-B irradiation to four (LDPE, HDPE, PP and PS), out of the most extensively used polymers, after specific time intervals of exposure. These studied polymers in the form of thin films were examined for their mechanical properties during UV artificial ageing, while their physicochemical and morphological alterations during UV exposure were also studied. The most significant alterations took place for PP in which noteworthy degradation occurred after only 5 days of exposure; a fact reinforced by its mechanical behavior. UV exposure deteriorated drastically LDPE, HDPE and PS after 10, 30 and 30 days respectively, while films became very brittle. This is due to the macromolecular chain scission caused from oxidation, as was verified with the aid of FTIR spectroscopy, and the formation of new carbonyl, vinyl and hydroxyl/hydroxyperoxide groups. According to SEM micrographs, defects and holes were gradually formed during UV aging, revealing extended decomposition. The latest observation is in well agreement with the findings of both the mechanical properties measurements and also PyGC/MS, according to which more vulnerable sites for thermal decomposition to be initiated were created throughout UV degradation, therefore resulting in the evolution of more small sized hydrocarbons.

Acknowledgments: This research was financially supported by the Greek Ministry of Development and Investments (General Secretariat for Research and Technology) through the research project "Intergovernmental International Scientific and Technological Innovation-Cooperation. Joint declaration of Science and Technology Cooperation between China and Greece" (Grant no: T7 $\Delta$ KI-00220).

Author Contributions: Methodology, investigation, formal analysis, N.M.A.; supervision, investigation, D.L.; supervision, investigation and editing, D.N.B.

Conflicts of Interest: The authors declare no conflict of interest.

\section{References}

1. Geyer, R.; Jambeck, J.R.; Law, K.L. Production, use, and fate of all plastics ever made. Sci. Adv. 2017, 3, 2529, doi:10.1126/sciadv.1700782.

2. Mao, R.; Lang, M.; Yu, X.; Wu, R.; Yang, X.; Guo, X. Aging mechanism of microplastics with UV irradiation and its effects on the adsorption of heavy metals. J. Hazard. Mater. 2020, 393, 122515, doi:10.1016/j.jhazmat.2020.122515.

3. Kedzierski, M.; D'Almeida, M.; Magueresse, A.; Le Grand, A.; Duval, H.; César, G.; Sire, O.; Bruzaud, S.; Le Tilly, V. Threat of plastic ageing in marine environment. Adsorption/desorption of micropollutants. Mar. Pollut. Bull. 2018, 127, 684-694, doi:10.1016/j.marpolbul.2017.12.059.

4. Bakaraki Turan, N.; Sari Erkan, H.; Onkal Engin, G. Microplastics in wastewater treatment plants: Occurrence, fate and identification. Process Saf. Environ. Prot. 2021, 146, 77-84, doi:10.1016/j.psep.2020.08.039.

5. Andrady, A.L. The plastic in microplastics: A review. Mar. Pollut. Bull. 2017, 119, 12-22, doi:10.1016/j.marpolbul.2017.01.082.

6. Burrows, S.D.; Frustaci, S.; Thomas, K.V.; Galloway, T. Expanding exploration of dynamic microplastic surface characteristics and interactions. TrAC-Trends Anal. Chem. 2020, 130, 115993, doi:10.1016/j.trac.2020.115993.

7. Cichy, B.; Kwiecieñ, J.; Pitkowska, M.; Ku, E.; Gibas, E.; Rymarz, G.; Ojeda, T.F.M.; Dalmolin, E.; Forte, M.M.C.; Jacques, R.J.S. PE-OXO Films under UV-B Radiation. 2015, 2015, 965-970, doi:10.1016/j.polymdegradstab.2009.03.011. 
8. Grigoriadou, I.; Pavlidou, E.; Paraskevopoulos, K.M.; Terzopoulou, Z.; Bikiaris, D.N. Comparative study of the photochemical stability of HDPE/Ag composites. Polym. Degrad. Stab. 2018, 153, 23-36, doi:10.1016/j.polymdegradstab.2018.04.016.

9. Bottino, F.A.; Cinquegrani, A.R.; Di Pasquale, G.; Leonardi, L.; Pollicino, A. Chemical modifications, mechanical properties and surface photo-oxidation of films of polystyrene (PS). Polym. Test. 2004, 23, 405411, doi:10.1016/j.polymertesting.2003.10.001.

10. Torikai, A.; Shirakawa, H.; Nagaya, S.; Fueki, K. Photodegradation of polyethylene: Factors affecting photostability. J. Appl. Polym. Sci. 1990, 40, 1637-1646, doi:10.1002/app.1990.070400919.

11. Gijsman, P.; Hennekens, J.; Janssen, K. Comparison of uv degradation of polyethylene in accelerated test and sunlight. Adv. Chem. Ser. 1996, 249, 618-620, doi:10.1021/ba-1996-0249.ch037.

12. Rodríguez-Vázquez, M.; Liauw, C.M.; Allen, N.S.; Edge, M.; Fontan, E. Degradation and stabilisation of poly(ethylene-stat-vinyl acetate): 1-Spectroscopic and rheological examination of thermal and thermooxidative degradation mechanisms. Polym. Degrad. Stab. 2006, 91, 154-164, doi:10.1016/j.polymdegradstab.2005.04.034.

13. Grigoriadou, I.; Paraskevopoulos, K.M.; Chrissafis, K.; Pavlidou, E.; Stamkopoulos, T.G.; Bikiaris, D. Effect of different nanoparticles on HDPE UV stability. Polym. Degrad. Stab. 2011, 96, 151-163, doi:10.1016/j.polymdegradstab.2010.10.001.

14. Devi, R.R.; Maji, T.K. Effect of Nano-ZnO on thermal, mechanical, UV stability, and other physical properties of wood polymer composites. Ind. Eng. Chem. Res. 2012, 51, 3870-3880, doi:10.1021/ie2018383.

15. Chrissafis, K.; Paraskevopoulos, K.M.; Pavlidou, E.; Bikiaris, D. Thermal degradation mechanism of HDPE nanocomposites containing fumed silica nanoparticles. Thermochim. Acta 2009, 485, 65-71, doi:10.1016/j.tca.2008.12.011.

16. Vuorinen, E.; Nhlapo, N.; Mafa, T.; Karger-Kocsis, J. Thermooxidative degradation of LDPE nanocomposites: Effect of surface treatments of fumed silica and boehmite alumina. Polym. Degrad. Stab. 2013, 98, 2297-2305, doi:10.1016/j.polymdegradstab.2013.08.011.

(C) 2020 by the authors. Submitted for possible open access publication under the terms and conditions of the Creative Commons Attribution (CC BY) license (http://creativecommons.org/licenses/by/4.0/). 